\title{
CONSIDERAÇÕES ACERCA DA DECISÃO DO SUPREMO TRIBUNAL FEDERAL BRASILEIRO SOBRE A INTERRUPÇÃO DA GRAVIDEZ EM CASOS DE ANENCEFALIA (ADPF 54)
}

\author{
Mônia Clarissa Hennig Leal ${ }^{1}$ \\ Universidade de Santa Cruz do Sul-Brasil \\ moniah@unisc.br
}

\section{CONSIDERA ÇÕES INICIAIS}

A tradição interpretativa ocidental tem se caracterizado por uma atuação de cunho marcadamente positivista, em que se verifica um exacerbado apego à lei, que, por sua vez, se evidencia por meio de uma hermenêutica extremamente restritiva, identificada por uma atividade silogística e simplista de contraste entre premissa maior (lei) e premissa menor (fato), onde o que importa é a validade do silogismo lógico, não havendo possibilidade de questionamento ou espaço interpretativo para uma reflexão acerca da verdade das próprias premissas.

Nesta perspectiva, a escola tradicional de interpretação se afigura como frágil em face das especificidades fáticas que envolvem e permeiam o direito e os conflitos sociais, demandando respostas efetivas que estas formas simplistas de interpretação muitas vezes não são capazes de dar ou, então, não são capazes de enfrentar satisfatoriamente, pois desconsideram a riqueza dos aspectos envolvidos no conflito que pretendem resolver.

1 Pós-Doutora em Direito pela Ruprecht-Karls Universität Heidelberg, Alemanha. Doutora em Direito pela Universidade do Vale do Rio dos Sinos - Unisinos, com pesquisa realizada junto à Ruprecht-Karls Universität Heidelberg, Alemanha. Pesquisadora conveniada da cátedra de Direito Público e do Estado da Ruprecht-Karls Universität Heidelberg, em parceria com o Prof. Dr. Winfried Brugger. Professora da disciplina de Jurisdição Constitucional do Programa de Pós-Graduação em Direito - M estrado e de Direito Constitucional na Graduação em Direito da Universidade de Santa Cruz do Sul - UNISC. Coordenadora do Grupo de Pesquisa "Jurisdição Constitucional aberta", vinculado e financiado pelo CNPq. Advogada. 
Assim, os problemas jurídicos são, antes de mais nada, também problemas fáticos, permeados por uma pluralidade de aspectos pragmáticos e por uma multiplicidade de variáveis que interferem (e devem interferir) na interpretação e que precisam, necessariamente, ser levados em consideração e explorados em suas potencialidades por ocasião de sua decisão jurídica.

Dentro deste contexto, ao se enfrentar um caso concreto, tem-se que ele deve, antes de mais nada, ser explorado em seus vários sentidos e significados, a fim de que sejam contemplados os seus aspectos de conexão com a vida social na qual se insere e da qual ele não pode ser desconectado, pois a historicidade e o caráter finalístico da norma se afiguram como essenciais e desempenham papel fundamental na compreensão do fato e do próprio direito.

É neste ponto, mais uma vez, que a teoria civilista tradicional, com seu método notadamente dedutivo, deixa a desejar, pois sua atuação é marcada por uma característica de fragmentação e de compartimentalização dos fatos e dos fenômenos, típica do sistema analítico de inspiração cartesiana, onde o todo não existe enquanto todo, mas apenas enquanto somatório de partes isoladas, cuja análise não leva em consideração a interação com as demais.

É com base em uma tal perspectiva que se pretende propor uma metodologia de estudo de caso mais adequada à complexidade das relações sociais e que leve em consideração as variáveis endógenas e exógenas das demandas.

Para tanto, a seguir propõe-se a análise de um caso específico referente à área do direito constitucional, apreciado e julgado pelo Supremo Tribunal em sede de liminar em Argüição de Descumprimento de Preceito Fundamental, na assim chamada ADPF 54. Trata-se de uma ação proposta pela Confederação Nacional dos Trabalhadores na Saúde (CNTS) e que versa sobre a possibilidade de autorização e de realização de aborto (ou, melhor dizendo, de interrupção da gestação) em casos de fetos com anencefalia.

Ao se analisar o caso, percebe-se que muitas questões envolvem a discussão, tais como a de se a Argüição de Descumprimento de Preceito Fundamental constitui o instrumento jurídico adequado para a demanda, se o feto anencefálico pode ser considerado como portador de vida humana e, portanto, se a interrupção da gravidez implicaria em prática de aborto ou não, bem como se a autorização de um eventual aborto, neste caso, implicaria em inclusão de uma nova excludente de ilicitude no Código Penal, que apenas o autoriza em duas situações específicas (risco de vida da mãe ou gravidez proveniente de estupro), a conseqüente possibilidade/necessidade de realização dessas cirurgias pelo sistema público de saúde, dentre outras.

A seguir, com base no julgamento em questão, passar-se-á a uma abordagem dos diferentes momentos que constituem a proposta metodológica aqui desenvolvida, no sentido de se aplicarem os fundamentos teóricos, trabalhados nos capítulos precedentes, a uma experiência concreta, recentemente vivenciada na realidade brasileira. 


\section{DO JULGAMENTO DA ADPF 54}

O caso concreto aqui selecionado como objeto de análise, conforme já referido, diz respeito à Ação de Descumprimento de Preceito Fundamental (ADPF 54), que a Confederação Nacional dos Trabalhadores na Saúde (CNTS) impetrou perante o Supremo Tribunal Federal em junho de 2004, pleiteando que se desse interpretação conforme à Constituição aos dispositivos do Código Penal que versam sobre o aborto, visando ao reconhecimento do direito subjetivo da mãe de realizar a interrupção da gravidez e à autorização de realização do parto antecipado, sem o risco de responsabilização criminal médica pelo ato praticado, havendo sido solicitada a concessão de liminar ${ }^{2}$ neste sentido, tendo-se em vista a urgência da medida e o risco de irreversibilidade da decisão.

A anencefalia é um defeito de formação do sistema nervoso fetal que ocorre entre o vigésimo terceiro e o vigésimo sexto dia de gestação, sendo que os bebês portadores desse tipo de problema nascem sem a maior porção do cérebro, enquanto que 0 tecido cerebral restante geralmente fica exposto, sem a proteção do crânio ou da pele. Por esta razão, a criança geralmente nasce cega, surda e sem consciência e não consegue sobreviver mais do que algumas horas. ${ }^{3}$ Segundo estimativas, a incidência do problema se dá em 4,6 casos a cada dez mil nascimentos; nos Estados Unidos, as estatísticas apontam que até dois mil bebês nascem com anencefalia a cada ano. ${ }^{4}$

Segundo alegação da entidade proponente da ação, a permanência do feto anômalo no útero da mãe é potencialmente perigosa, podendo gerar danos à saúde da gestante e até mesmo perigo de vida, em razão do alto índice de óbitos intra-uterinos desses fetos, constituindo a antecipação do parto, nesses casos, uma indicação terapêutica médica.

Reforçando os argumentos trazidos na inicial, sustentou-se a inviabilidade da vida extra-uterina desses fetos, em face do que a antecipação do parto não conformaria aborto, diferenciando-se a situação, ainda, do assim chamado aborto "eugênico", que tem por fundamento a percepção de alguma eventual anomalia ou doença da criança.

Assim, a CNTS requereu que fosse dada interpretação conforme à Constituição aos arts. 124, 126 e 128 do Código Penal, para explicitar que a disciplina legal do aborto não se aplica aos casos de antecipação terapêutica do parto em casos de anencefalia.

A lém disso, uma vez constatada a total inviabilidade da vida extra-uterina, o posicionamento aduzido foi o de que, neste caso, a preocupação deveria ser transferida

2 A concessão de liminar em sede de Argüição de Descumprimento Fundamental encontra respaldo no

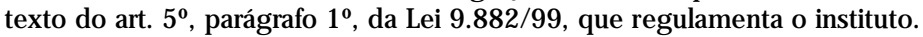

3 A pesar dessas mal-formações, contudo, os outros órgãos muitas vezes aparecem completos e perfeitos, podendo ser doados.

4 Conforme dados constantes no Jornal Folha de São Paulo. Cf. Folha OnLine (2007): Saiba mais sobre a anencefalia, [fecha de consulta: 24 de noviembre de 2007]. Disponible em: http://www.folhaonline.br. 
para a gestante, submetida a tortura psicológica por ser obrigada a carregar um feto que se sabe ser incapaz de viver (ofensa à dignidade humana). Foi invocada, também, ofensa ao princípio da legalidade, segundo o qual "ninguém será obrigado a fazer ou deixar de fazer alguma coisa senão em virtude de lei" (art. 50, inciso II da Constituição de1988), sustentando-se que a antecipação terapêutica do parto não é vedada pelo ordenamento jurídico brasileiro, bem como ao direito à saúde, já que a antecipação do parto constitui a única forma de se abreviar a dor da gestante.

Já do ponto de vista formal, a propositura da ação se justifica em razão do fato de que, apesar de os Tribunais brasileiros, por reiteradas vezes e em todo o país, terem autorizado a realização de partos nessas condições, algumas decisões em contrário também vinham sendo verificadas, gerando, assim, insegurança e incerteza quanto à sua prática. ${ }^{5} \mathrm{Em}$ face disso, um dos principais pontos em questão consistiu na uniformização da jurisprudência, já que, no caso, a posição do STF teria efeito vinculante, erga omnes, aplicando-se, indistintamente, a todas as situações dessa natureza, que passariam a independer de uma autorização judicial específica e individual para cada caso, como vinha ocorrendo.

Em seu parecer, por outro lado, a Procuradoria-Geral da República refutou os argumentos aduzidos na inicial, fundando-se, basicamente, na questão da inadequação da figura da interpretação conforme à Constituição ao caso em tela e na primazia do direito à vida.

Segundo a PGR, os artigos do Código Penal questionados não se prestam à interpretação conforme à Constituição, pois bastam-se no que enunciam, havendo, ainda, necessariamente, limites ao uso do instituto em questão, sob pena de se usurparem funções propriamente legislativas; conforme sustentado, o sentido literal da lei não constitui, por si só, limite à interpretação, mas ela não pode se converter em um instrumento de revisão do direito posto, sendo vedado, pois, aos juízes, por essa via, fazer uma nova lei com conteúdo diferente da anterior, sob pena de violar-se o princípio da separação dos poderes.

A demais, o parquet federal fez alusão ao fato de que a anencefalia não se enquadra nas excludentes de ilicitude previstas no Código Penal, pois não há, neste caso, risco de vida por parte da mãe. Por fim, referiu que, se há gestação, há vida intra-uterina, sendo esta protegida, no direito brasileiro, desde a concepção (art. $2^{\circ}$ do Código Civil brasileiro) e conformando-se o direito à vida, no caso, como marco primeiro dos direitos fundamentais, não podendo ele ser medido pelo tempo, isto é, o eventual sofrimento da gestante não conforma um elemento de peso suficiente para se contrapor a isso (em caso de um juízo de ponderação de bens).

\footnotetext{
A primeira decisão judicial no Brasil autorizando uma gestante a interromper a gravidez por anencefalia do bebê aconteceu em Rondônia, em 1989. Estima-se que, no Brasil, já tenham chegado ao Judiciário cerca de três mil casos de anencefalia, sendo que, em $97 \%$ das ações, os juízes autorizaram a interrupção da gravidez. Cf. FOLHA ONLINE (2007). Juízes reconhecem aborto de feto sem cérebro desde 1989, [fecha de consulta: 24 noviembre 2007]. Disponible en: http://www.folhaonline.br.
} 
Por fim, invocando o princípio da solidariedade insculpido no art. 3ำ inciso I, da Constituição brasileira, o Procurador-Geral da República, Claudio Fontelles, afirmou que a antecipação do parto impede a doação de órgãos, privando-se, dessa forma, outras crianças de poderem viver normalmente.

No caso, o M inistro Marco Aurélio M ello, relator do processo, concedeu a liminar, entendendo tratar-se de situação que "foge à glosa própria do aborto", utilizando-se, para tanto, dos seguintes argumentos, submetendo a concessão da medida ao posterior crivo do Plenário:

Há, sim, de formalizar-se medida acauteladora, e esta não pode ficar limitada à mera suspensão de todo e qualquer procedimento judicial hoje existente. Há de viabilizar, embora de modo precário e efêmero, a concretude maior da Carta da República. Daí o acolhimento do pleito formulado para, diante da relevância do pedido e do risco de manter-se com plena eficácia o ambiente de desencontro em pronunciamentos judiciais até aqui notados, ter-se não só o sobrestamento dos processos e decisões não transitadas em julgado, como também o reconhecimento do direito constitucional da gestante de submeter-se à operação terapêutica de parto de fetos anencefálicos, a partir de laudo médico atestando a deformidade, a anomalia que atingiu o feto. É como decido na espécie. ${ }^{6}$

Interessante notar, neste sentido, que um dos fundamentos para uma tal postura residiu na compreensão de que a interrupção da gravidez, em casos de fetos anencefálicos, não conforma aborto. Este aspecto constitui, por sua vez, na forma em que proposto no presente estudo, um dos aspectos controversos de apreciação, de operacionalização e de resolução do caso concreto, que será analisado mais adiante.

Uma vez indo a Plenário, contudo, a liminar foi derrubada por sete votos a quatro. Dentre os que votaram de forma contrária à medida, com base em argumentos bastante diversos, o M inistro Eros Roberto Grau sustentou que a decisão criava uma nova forma de aborto permitido, pois o Código Penal autoriza o aborto apenas nos casos de estupro ou de risco de vida da mãe. Já o M inistro Cezar Peluso contestou o argumento com base na compreensão de que não há razão para a antecipação, já que "todos nascemos para morrer". Votaram, ainda, pela derrubada da liminar, os M inistros Joaquim Barbosa, Gilmar Ferreira Mendes, Ellen Gracie Northfleet, Carlos Velloso e Nelson Jobim. Em sentido contrário, confirmando a decisão do M inistro M arco A urélio, os M inistros Carlos A yres Britto, Celso de M ello e Sepúlveda Pertence. Independentemente do resultado do julgamento, contudo, o plenário decidiu, por maioria, pela manutenção da suspensão dos processos criminais que tramitavam na Justiça contra grávidas e profissionais que haviam realizado cirurgias desse tipo.

6 BRASIL. Supremo Tribunal Federal (2004): Questão de Ordem em Argüição de Descumprimento de Preceito Fundamental 54-8/Distrito Federal. Relator M inistro Marco Aurélio M ello, julgada em 20 out. 2004. Disponible em: http://www.stf.gov.br. 
Em momento posterior, encerradas as discussões travadas no âmbito da liminar, o Supremo Tribunal Federal teve, ainda, antes de chegar ao julgamento de mérito propriamente dito, que decidir pelo conhecimento da ação. Neste ponto, a questão controvertida residia, por sua vez, no cabimento da Argüição de Descumprimento de Preceito Fundamental para o caso e na possibilidade de o Supremo Tribunal Federal decidir ou não o mérito de um tal pedido, pois, conforme alguns, isto implicaria, em última instância, na criação - pela via jurisprudencial- de uma terceira possibilidade não-punível de aborto, além daquelas tradicionalmente previstas pelo Código Penal, casos tidos como legais, isto é, casos em que o aborto não é tipificado como crime. Dito de outra forma, segundo os argumentos suscitados, o Supremo, ao determinar uma tal hipótese, acabaria tomando medidas que, tradicionalmente, caberiam à atividade legislativa, do que resultaria uma usurpação de competências e, conseqüentemente, uma violação da separação de poderes tradicionalmente estabelecida.

Esta discussão traz implícita, por sua vez, uma discussão muito comum no âmbito da teoria constitucional européia -notadamente de parte da teoria constitucional alemã e americana-, que tem na reflexão sobre a legitimidade de atuações semelhantes por parte dos Tribunais Constitucionais um de seus principais focos. Comumente, podem-se identificar, neste sentido, duas correntes opostas no enfrentamento da questão: uma de caráter restritivo, que vê nos atos da jurisdição constitucional uma violação e uma exacerbação das funções judiciais, e outra de caráter expansivo, que atribui aos Tribunais Constitucionais um papel destacado na proteção dos conteúdos constitucionais. ${ }^{7}$

Por fim, em julgamento realizado no dia 27 de abril de 2005, o Supremo Tribunal Federal decidiu, em apertada votação de sete a quatro votos, pelo cabimento da A rgüição de Descumprimento de Preceito Fundamental proposta (ADPF 54). ${ }^{8}$

A controvérsia, contudo, ao contrário do que se poderia pressupor inicialmente, não se travou, exatamente, com relação ao mérito da questão, isto é, o ponto controvertido não residiu na apreciação da legalidade ou não do aborto nos casos em que 0 feto, sabidamente, não possui cérebro e, portanto, não possui condições de sobrevida após o nascimento. Antes pelo contrário, tratou-se, nesta votação, da questão preliminar que envolvia o recebimento ou não da ação proposta, ou seja, o que estava em jogo era a possibilidade ou não de o Supremo Tribunal Federal julgar uma ação envolvendo tal conteúdo, pela via em que foi proposta.

Dito de outro modo, a questão pressupunha uma análise acerca de se a A rgüição de Descumprimento de Preceito Fundamental, instituída e assegurada pela Constituição brasileira (art. 102, parágrafo 1으), poderia ser utilizada como instrumento para se ques-

\footnotetext{
Para um aprofundamento sobre o tema, ver LEAL, M ônia Clarissa Hennig (2007): Jurisdição Constitucional aberta: reflexões sobre a legitimidade e os limites da jurisdição constitucional na ordem democrática - uma reflexão a partir das teorias constitucionais alemã e norte-americana, (Rio de Janeiro, Lumen Juris).

8 En: http://www.stf.gov.br/noticias/imprensa/ultimas.
} 
tionar a falta de previsão, na lei, de uma tal possibilidade de interrupção da gestação. Isto porque esta ação é destinada a viabilizar, numa dimensão objetiva, ${ }^{9}$ a realização jurisdicional de direitos básicos e de preceitos fundamentais contemplados pelo texto constitucional, mas que, por motivos legais (ou em decorrência da ausência deles) não podem ser exercidos ou usufruídos, descumprindo-se, assim, a própria Constituição. ${ }^{10}$

Sustentando entendimento contrário àquele manifestado pelo relator, o M inistro Carlos Ayres Britto, negando, portanto, a possibilidade de julgamento do mérito, a minoria composta pelos M inistros Eros Roberto Grau, Cezar Peluso, Ellen Gracie Northfleet e Carlos Velloso pautou seu posicionamento no argumento de que o Tribunal estaria criando, por via oblíqua, uma nova hipótese de não-punibilidade do aborto, o que o transformaria em legislador positivo e, conseqüentemente, violaria a sua função, concebida, nos casos da jurisdição concentrada idealizada por Kelsen, ${ }^{11}$ para se dar em um sentido meramente negativo.

Em sua teoria acerca do controle de constitucionalidade -marcadamente concentrado em um órgão específico, ao contrário do modelo difuso da judicial review americana- o autor austríaco idealizou esta função não como uma atividade propriamente judicial, senão como sendo de "legislação negativa", a partir do momento em que cabe a ele analisar, tão-somente e em abstrato, o problema de compatibilidade lógica entre a lei e a norma constitucional. ${ }^{12}$

Nesta perspectiva, a criação de leis e de tipos criminais seria competência exclusiva do Poder Legislativo, que, enquanto órgão representativo e democrático, teria a função de apreciar os valores sociais e convertê-los em normas jurídicas, restando ao órgão de controle a verificação da compatibilidade ${ }^{13}$ ou não destas normas com a Constituição enquanto norma superior hierárquica do ordenamento jurídico.

9 Diz-se que a Argüição de Descumprimento de Preceito Fundamental possui uma dimensão objetiva porque ela não possui partes. Cf. FrEIRE, A lexandre Reis Siqueira (2001): “Argüição de Descumprimento de Preceito Fundamental: origem e perspectivas", en Revista da Faculdade de Direito da UFPR (Porto Alegre, ano 33, v. 35), pp. 205-218.

10 MandelLI Junio, Roberto Mendes (2003): Argüição de Descumprimento de Preceito Fundamental: instrumento de proteção dos direitos fundamentais e da Constituição, (São Paulo, Revista dos Tribunais).

11 Neste sentido ver o texto de KELSEN, Hans (1929): Wesen und Wert der Demokratie, (Tübingen, Mohr), p. 57.

12 KelSen, Hans (1929): "Wer soll der Hüter der Verfassung sein?", en Die Justiz, (Heft 11-12, vol. VI), pp. 576-628.

13 Esta discussão sobre os limites de atuação da jurisdição constitucional no sentido de garantia da Constituição, por mais que pareça ter aparecido de forma contundente tão-somente agora, já é, contudo, objeto de inúmeras construções doutrinárias na teoria constitucional alemã e norte-americana, onde o tema aparece na dicotomia substancialismo x procedimentalismo, conforme se defenda ou se rejeite, respectivamente, uma atuação mais ampla dos Tribunais Constitucionais neste sentido. Cf. LEAL, M ônia Clarissa Hennig (2007): Jurisdição Constitucional aberta: reflexões sobre a legitimidade e os limites da jurisdição constitucional na ordem democrática - uma reflexão a partir das teorias constitucionais alemã e norte-americana (Rio de Janeiro, Lumen Juris). 
Assim, em face dos argumentos suscitados, têm-se como controvertidos os seguintes pontos, que demandam uma apreciação fático-teórica mais detalhada acerca de sua significação para o caso concreto:

a) O cabimento e os limites, em face de suas características, da figura da interpretação conforme à Constituição aos dispositivos do Código Penal questionados (anteriores, inclusive, à própria Constituição), bem como a legitimidade do Supremo Tribunal Federal em decidir dessa forma, em face da separação de poder (questão prévia para determinar o conhecimento da ação).

b) A definição sobre a real condição do feto, isto é, se a interrupção da gestação poderia ser enquadrada no tipo penal do aborto ou não e, mais do que isso, se ele constitui um sujeito de direito e, conseqüentemente, um sujeito de dignidade protegido pelo ordenamento jurídico-constitucional brasileiro.

c) Em sendo considerado um sujeito de dignidade, como operacionalizar este eventual conflito do direito à vida do feto com o direito à saúde e de dignidade da mãe (ponderação e proporcionalidade).

Uma vez fixados estes aspectos controversos, que conformam o elemento central sobre o qual se desenvolve a análise do caso concreto, passaremos, agora, a examinar pontualmente cada um desses pontos, cotejando-os com a argumentação trazida e os referenciais teóricos atinentes.

\section{SIGNIFICADO NO CASO CONCRETO, ABORDA GEM DOS ELEMENTOS DOGM ÁTICO-POSITIVOS E REPERCUSSṌES EPISTEM OLÓGICAS DO EXAME DO SIGNIFICADO A PARTIR DO CASO CONCRETO}

Primeiramente, conforme a metodologia proposta neste trabalho, a análise de um caso concreto demanda que se analise a natureza do conflito, isto é, que se analise o que, efetivamente, está em jogo naquele determinado processo ou demanda. Somado a isso, conforme os passos metodológicos que constituem o presente método de resolução de casos concretos, a abordagem dos elementos dogmático-positivos pressupõe, ainda, uma compreensão do sistema jurídico e de sua operacionalização como um todo, sendo complementada, em seguida, por uma identificação das posições doutrinárias e jurisprudenciais atinentes ao tema.

Perceber, todavia, quais os interesses e qual a extensão e repercussão da causa muitas vezes não constitui tarefa fácil, notadamente para aquele operador jurídico forjado ainda em bases positivistas, preparado para conhecer as leis e os códigos, mas muitas vezes desconectado das reais implicações e necessidades envolvidas na controvérsia jurídica.

No caso sob comento, muitos são os conceitos jurídicos envolvidos, determinantes para a solução da lide, conforme identificado no tópico anterior, desde a extensão 
e os limites da aplicabilidade do instituto da interpretação conforme à Constituição, passando pela compreensão do que significa a anencefalia e de se a interrupção da gestação, nestes casos, configura aborto ou não, até as possibilidades de ponderação entre os princípios constitucionais envolvidos.

\section{a) As possibilidades de aplicação do instituto da interpretação conforme à Constituição ao caso}

Como já referido, a primeira questão a ser analisada diz respeito à possibilidade de se dar interpretação conforme à Constituição aos dispositivos contidos nos arts. 124, 126 e 128 do Código Penal, visando a explicitar que a disciplina legal do aborto não se aplica aos casos de antecipação terapêutica do parto em casos de anencefalia.

A interpretação conforme à Constituição (verfassungskonforme Auslegung do direito alemão) conforma um princípio interpretativo diretamente decorrente da própria supremacia constitucional que identifica os Estados Democráticos, servindo, nesta perspectiva, como vetor hermenêutico e como parâmetro para a interpretação de todas as demais normas do ordenamento jurídico. Significa dizer que, em face do processo de constitucionalização ${ }^{14}$ que marca o atual estágio de desenvolvimento da ciência jurídica ocidental. Assim, segundo esta perspectiva, nenhuma norma pode ser interpretada de forma contrária ao sentido do texto constitucional, impondo-se uma interpretação que potencialize os seus conteúdos, realizando os fins por ela propostos. Resulta, daí, uma vinculação de todo o ordenamento ao que estabelece a Constituição, ${ }^{15}$ abrindo-se espaço, desta forma, para a construção da idéia de "interpretação conforme à constituição" e que passa a ser compreendida como imperativa para a compreensão e aplicação de qualquer legislação e/ou ato normativo.

Tem-se, pois, aqui, o aparecimento de tal instituto desempenhando o papel de princípio hermenêutico e interpretativo, concepção reforçada por Hesse ${ }^{16}$ ao inseri-

${ }_{14} 0$ fenômeno de constitucionalização do direito pode ser percebido em diferentes manifestações, encontrando, talvez, a sua principal marca na chamada "constitucionalização do direito privado", tido como a "última fronteira", e que reflete a influência deste processo ao passar a trabalhar com noções como a de função social da propriedade e do contrato, de vinculação dos particulares aos direitos fundamentais, dentre outras. Sobre os aspectos teóricos que identificam estas novas construções, ver as obras de HESSE, Konrad (1995): Derecho Constitucional y Derecho Privado, (Traducc. Ignacio Gutiérrez Gutiérrez, Madrid, Civitas), p. 73; SARLET, Ingo Wolfgang (2000): A Constituição concretizada: construindo pontes entre o público e o privado, (Porto Alegre, Livraria do Advogado) e ANDRADE, André (2003): A constitucionalização do Direito: a Constituição como locus da hermenêutica jurídica, (Rio de Janeiro, Lumen Juris).

15 Esse fonômeno é designado, pela teoria constitucional alemã, como Ausstrahlungswirkung. Neste sentido DreIER, Ralf (1988): “Konstitutionalismus und Legalismus: zwei Arten juristischen Denkens im demokratischen Verfassungsstaat", en Rechtsstaat und Menschenwürde. Festschrift für Werner Maihofer zum 70. Geburstag, (Frankfurt a.M., Klostermann), p. 91.

16 HesSE, Konrad (1999): Grundzüge des Verfassungsrechts der Bundesrepublik Deutschland, (20. Auflage, Heidelberg, C. F. Müller), p. 30. 
lo, em sua obra de referência, exatamente no capítulo dedicado à interpretação constitucional. ${ }^{17}$

Ao mesmo tempo, contudo, este instituto, que se inclui entre as sentenças ditas interpretativas, ${ }^{18}$ pode ser entendido, igualmente, como uma forma de preservação do legislador ${ }^{19}$ (e, por via de conseqüência, como um importante instrumento de preservação da autonomia e da separação entre os poderes), ao assumir, como decorrência lógica, que um preceito legal somente pode ser declarado inconstitucional ${ }^{20}$ quando não admitir uma interpretação que se coadune com o conteúdo constitucionalmente indicado, ${ }^{21}$ situação em que se pode perceber, como já foi dito, ainda que não

17 O tema da interpretação constitucional (Verfassungsinterpretation), assentado na exploração das complexidades e peculiaridades que caracterizam este novo constitucionalismo, numa tentativa de superação da tradição interpretativa historicamente estabelecida para o direito público, que sempre tendeu a pretender incorporar os métodos e estratégias próprios do direito privado, aparece, agora, como uma preocupação específica no sentido de dotar o Direito Constitucional de instrumentos e de referenciais teóricos condizentes com a importância e materialidade que Ihe são próprios. Um esforço com relação a este aspecto pode ser percebido nas reflexões dos principais constitucionalistas alemães pioneiros na sistematização de tais questões, seguidos pela doutrina do próprio Tribunal Constitucional, aberto a tais construções - tais como Konrad Hesse, Friedrich Müller, Ernst-Wolfgang Böckenförde, dentre outros, que dedicaram especial atenção à questão, com artigos e produções especificamente voltadas para discussão dessa temática.

18 A doutrina constitucional costuma diferenciar, neste sentido, as sentenças interpretativas (em que a manipulação e atuação do Tribunal se dirige exclusivamente a aspectos interpretativos da norma) e as sentenças ditas manipulativas (em que a atuação do Tribunal altera e manipula o próprio texto normativo, a fim de torná-lo condizente com a Constituição). Estas expressões foram cunhadas, inicialmente, pela doutrina italiana, conforme se pode depreender da leitura de ZAGREBELSKY, Gustavo (1988): La giustizia constituzionale, (2. ed., Bolonia, II Mulino), p. 296.

Sobre as características que marcam cada uma destas sentenças, ver o texto de A BeLLÁn, Marina Gascón (2003): "Los límites de la jurisdicción constitucional”, en LAPORTA, Francisco (org.). Constitución: problemas filosóficos, (Madrid, Centro de Estudios Políticos y Constitucionales), p. 177. Também StRECK, Lênio Luiz (2001): "Os meios e acesso do cidadão à jurisdição constitucional, a Argüição de Preceito Fundamental e a crise de efetividade da Constituição brasileira", en SouzA CRUz, Álvaro Ricardo de (org.). Hermenêutica e jurisdição constitucional, (Belo Horizonte, Del Rey), p. 249.

19 Brünneck inclui a interpretação conforme à Constituição como uma variante da figura do judicial restraint, ao lado do chamado "apelo ao legislador" (Appellentscheidung). Cf. BRÜNnECK, Wiltraut Rupp-von (1977): "Verfassungsgerichtsbarkeit und gesetzgebende Gewalt: wechselseitiges Verhältnis zwischen Verfassungsgericht und Parlament", en Archiv des öffentlichen Rechts, (Band 102, Tübingen, J.C.B. Mohr), p. 20. Na doutrina pátria, estes temas são abordados por Gilmar Ferreira Mendes, que atribui ao aqui citado autor alemão o primeiro escrito sobre a Appellentscheidung na teoria alemã. Cf. MENDES, Gilmar Ferreira (1998): Jurisdição constitucional: o controle abstrato de normas no Brasil e na Alemanha, (2. ed., São Paulo, Saraiva), p. 230.

20 "Eine weitere Entscheidungsform hat sich das Gericht selbst zugelegt, indem es eine Rechtsnorm nicht wegen Verfassungswidrigkeit für nichtig erklärt, sondern lediglich ihre 'Unvereinbarkeit' mit der Verfassung feststellt und in der Regel die Nichtigkeit als Folge der Verfassungswidrigkeit erst eintreten lässt, wenn das Gesetz nicht innerhalb einer von inm gesetzten Frist entsprechend geändert wird." De forma resumida, significa que o Tribunal mesmo desenvolveu -e, com isso, conseqüentemente ampliou sua atuação- uma forma de decisão em que uma norma só é declarada inconstitucional se, mesmo após manifestada a sua incompatibilidade com a Constituição (o que ocorre previamente), ela não é legislativamente modificada. Cf. BRонм, Winfried (2001): "Die Funktion des BVerfG - Oligarchie in der Demokratie?", en Neue Juristische Wochenschrift, (Heft 01), p. 02.

21 "Nach dem Grundsatz ist ein Gesetz nicht für nichtig zu erklären, wenn es im Einklang mit der Verfas- 
de forma absoluta (pois o que está em jogo é uma interpretação que não se vincula ou restringe à intenção originária do legislador), um princípio de conservação das leis. ${ }^{22}$

Ao mesmo tempo, contudo, segundo a teoria que se desenvolveu com relação ao instituto, deve-se registrar que o texto normativo se estabelece como um limite para esta atuação, não comportando interpretações contra legem, ainda que fundadas na Constituição. Dito de outra forma, tem-se que o recurso à interpretação conforme não pode contrariar o sentido inequívoco que se extrai da fórmula normativa sob apreço. ${ }^{23}$

Diante de tais aspectos, conclui-se que a interpretação conforme, enquanto forma especial de interpretação sistemática ${ }^{24}$ que é, ao mesmo tempo em que reflete a supremacia da Constituição, constitui, também, na via contrária, instrumento importante para a consecução e concretização dessa mesma supremacia.

De outro lado, pode-se perceber que a figura da interpretação conforme à Constituição permite ser entendida, também, como um importante mecanismo de controle de constitucionalidade, ${ }^{25}$ ao ser empregada, pelos Tribunais, ${ }^{26}$ como critério para a exclusão de eventuais sentidos possíveis com relação à norma. ${ }^{27}$

sung ausgelegt werden kann." BverfGE 93, 37. GRIM M, Dieter; KIRCHHOF, Paul (1997): Entscheidungen des Bundesverfassungsgerichts. Studien-auswahl, (2. Auflage, Bearbeitet von Michael Eichenberger, Tübingen, Mohr), p. 652.

22 AbelLÁN, Marina Gascón (2003): "Los límites de la jurisdicción constitucional”, en LAPORTA, Francisco (org.). Constitución: problemas filosóficos, (M adrid, Centro de Estudios Políticos y Constitucionales), p. 175.

23 STRECK, Lênio Luiz (2002): Jurisdição constitucional e hermenêutica: uma nova crítica do Direito (Porto Alegre, Livraria do Advogado), p. 454.

24 Note-se que a referência à interpretação sistemática não é feita, aqui, em seu sentido clássico enquanto método de interpretação, em sua concepção identificada por Savigny ao lado dos métodos gramatical e teleológico, dentre outros. Ela é identificada, antes, como sistemática, neste contexto, por se valer da referência ao "todo" material da Constituição em sua função.

25 Para Streck, a figura da interpretação conforme funciona, inclusive, como pré-questionamento, se alegada ou suscitada pela parte. Cf. STRECK, Lênio Luiz (2002): Jurisdição constitucional e hermenêutica: uma nova crítica do Direito, (Porto Alegre, Livraria do Advogado), p. 444.

26 Este aspecto fica evidenciado em algumas decisões proferidas pelo próprio Supremo Tribunal Federal, que deixa transparecer, em certos momentos, ser esta uma prerrogativa do controle concentrado de constitucionalidade (Recurso Extraordinário no 184.093/SP). Cf. também RosA, Eugenio (2003): “Interpretação conforme a Constituição e controle difuso de constitucionalidade", en ANDRADE, André (org.). A constitucionalização do Direito: a Constituição como locus da hermenêutica jurídica, (Rio de Janeiro, Lumen Juris), p. 159.

27 A corroboração de uma tal compreensão pode ser encontrada nos relatos de José Adércio Leite Sampaio, ao analisar a evolução do referido instituto pela teoria constitucional alemã: "A doutrina e a jurisprudência alemãs, com vistas à defesa da supremacia constitucional, por um lado, e da presunção de legitimidade constitucional da lei por outro, desenvolveram a doutrina da interpretação conforme com a Constituição, tanto como técnica de salvaguarda da constitucionalidade das leis, como método de interpretação constitucional, vedando, nesse caso, que o entendimento e alcance das normas constitucionais fossem definidos a partir de leis." Cf. SAmpalo, José Adércio Leite (2002): A Constituição reinventada pela Jurisdição Constitucional (Belo Horizonte, Del Rey), p. 829.

Em sentido diverso, percebendo $o$ instituto a partir de uma função notadamente de controle de constitucionalidade, tem-se o pensamento de MIRANDA, Jorge (2000): Manual de Direito Constitucional, (4. ed., Coimbra, Coimbra), p. 267. 
Em outras palavras, para evitar a declaração de nulidade de determinada lei, o Tribunal se vale de suas prerrogativas interpretativas para estabelecer, dentre os conteúdos possíveis, aquele que melhor se coaduna com a Constituição, isto é, como determinada norma deve ser entendida para que não seja tida como inconstitucional, ou, ainda, qual das possíveis interpretações se revela compatível com a Lei Fundamental. ${ }^{28}$

No caso em tela, a aplicação da interpretação conforme à Constituição somente pode ser compreendida no primeiro sentido aqui trabalhado, isto é, numa perspectiva hermenêutica, pois, realmente, na situação concreta verificada, não há, de parte dos dispositivos constitucionais suscitados, qualquer plurivocidade ou dubiedade que possa dar margem a entendimentos ou interpretações contrários à Constituição, em seu sentido de mecanismo de controle de constitucionalidade.

Este aspecto foi ressaltado, por sua vez, no parecer da Procuradoria Geral da República, que sustentou não ser a interpretação conforme à Constituição o instrumento adequado para o pleito. Trata-se, realmente, mais de uma questão meramente interpretativa (se a antecipação do parto pode ser considerada aborto ou não -isto é, se há vida e gestação propriamente dita, ou não- tipicidade do direito penal (o que remete à discussão do próximo tópico), e não de interpretação conforme (inclusão de nova excludente de ilicitude no sentido de uma sentença interpretativa e/ ou manipulativa, conforme explicitado acima).

Além dos fatores já ressaltados, é preciso levar-se em consideração, ainda, para fins de avaliação e de localização social do problema, que, ao dizer respeito a um tema delicado como é o da interrup ção da vida ou de uma potencial vida, indubitável estarem envolvidas aí, também, uma série de variáveis sociais, políticas e culturais, reforçando-se, desta forma, o elemento de complexidade já anteriormente ressaltado.

Com relação a este aspecto, pode-se facilmente perceber que muitas questões advêm do julgamento em questão, sendo o próximo aspecto a ser analisado, conforme já referido, o da definição sobre a real condição do feto, isto é, se a interrupção da gestação poderia ser enquadrada no tipo penal do aborto ou não e, mais do que isso, se ele constitui um sujeito de direito e, conseqüentemente, um sujeito de dignidade protegido pelo ordenamento jurídico-constitucional brasileiro.

\section{b) A tipicidade penal da antecipação terapêutica do parto}

0 direito positivo e, sobretudo, o direito penal, encontra-se embasado no que se poderia denominar de "teoria do tipo penal", isto é, a tipicidade constitui o elemento central da conformação da ilicitude, pressupondo a prática de um crime, sempre, que 0 ato constitua fato típico e contrário ao direito. E é exatamente esta teoria do tipo

28 Neste sentido M ENDES, Gilmar Ferreira (1998): Jurisdição constitucional (2. ed., São Paulo, Saraiva), p. 221. 
penal que entra em questão quando se trata do caso em tela. Conforme o Código Penal, conforma crime de aborto 0 ato de interrupção da gravidez com a conseqüente morte do feto.

Em face das complexidades fáticas e até mesmo jurídicas que envolvem o caso, há a necessidade de se analisar até que ponto a antecipação do parto, neste caso, poderia ser interpretada como aborto. Primeiramente, a tipicidade, no crime de aborto, requer a ocorrência de interrupção da vida do feto; nos casos de anencefalia, contudo, o conceito de vida acaba sendo questionado, já que o feto é desprovido de atividade cerebral. Neste ponto, ressurge uma questão reiteradamente polêmica e desafiadora para o direito, que é a delimitação jurídica do conceito de vida humana, aspecto reiteradamente suscitado quando os problemas jurídicos envolvem questões controversas como a eutanásia ${ }^{29}$ em casos de vida vegetativa e até mesmo a possibilidade de transplante de órgãos.

No caso do direito brasileiro, não há, do ponto de vista legislativo, uma formulação clara do que conforma a vida, porém há alguns elementos que permitem que se vislumbrem alguns indicativos a respeito. A pesar de a prática da eutanásia, reiteradamente, ser encarada como homicídio em face de nosso ordenamento jurídico, no caso do transplante de órgãos, ${ }^{30}$ por exemplo, a morte cerebral é reconhecida como critério suficiente para se autorizar a retirada dos mesmos, sendo esta, portanto, uma hipótese em que a atividade cerebral é considerada como um requisito essencial à noção de vida.

Este impasse conceitual foi percebido, de certa forma, pelos M inistros Carlos Ayres Britto e Cezar Peluso, que, em seus votos, se ocuparam do enfrentamento da questão. Para o primeiro, não haveria óbice jurídico à interrupção da gestação (e, portanto, também não haveria repercussão na esfera penal) nos casos de anencefalia porque, nestes casos, sequer há vida ${ }^{31}$-entendida, aqui, como estritamente vinculada à existência de atividade cerebral- razão pela qual não haveria que se falar em aborto, pois, como a existência de vida intra-uterina conforma requisito essencial à tipicidade, sua ausência, do ponto de vista jurídico, tornaria a conduta médica e da própria gestante atípica do ponto de vista penal.

Já para o Ministro Cezar Peluso, a analogia com a morte encefálica no caso de doação de órgãos não se faz possível, porque, nesse caso, o ato se justifica em razão do fato de que é destinado para salvar vidas, ${ }^{32}$ fato que justificaria a prática em ques-

29 Este tema é objeto de reflexão de um ramo cada vez mais em evidência no âmbito do Direito, que é o Biodireito. Para um aprofundamento dos aspectos que envolvem estas questões, ver DıNız, Maria Helena (2001): O estado atual do Biodireito, (São Paulo, Saraiva).

30 Art. 30 da Lei 9.434/97.

31 BRASIL. Supremo Tribunal Federal (2004): Medida Cautelar na Argüição de Descumprimento de Preceito Fundamental 54-8/Distrito Federal, (Relator M inistro M arco Aurélio M ello, julgada em 20 out. 2004), p. 72.

32 BRASIL. Supremo Tribunal Federal (2004): Medida Cautelar na Argüição de Descumprimento de Preceito Fundamental 54-8/Distrito Federal (Relator M inistro Marco Aurélio M ello, julgada em 20 out. 2004), p. 76. 
tão. 0 julgador parece desconsiderar, no entanto, a máxima do imperativo categórico kantiano ${ }^{33}$ de que o ser humano precisa ser considerado como sendo um fim em si mesmo, e jamais como instrumento ou meio para a realização de um determinado fim. Ou seja: a situação, no caso do transplante e da antecipação do parto nos casos de fetos anencefálicos, é idêntica, contudo a primeira se justifica pela natureza solidária de que se reveste, ao passo que a segunda não. Não fica claro, na argumentação tecida por ocasião do voto, todavia, se esta relativização se dá em face de uma ponderação em face da importância e relevância dos interesses contrários (juízo de proporcionalidade, que sequer é desenvolvido) ou se é a própria ausência de atividade cerebral que autoriza a retirada dos órgãos.

0 que se pode perceber, portanto, em face do que foi exposto com relação a esse ponto, é que há um importante papel reservado à interpretação neste processo, pois, dependendo do que se entende por vida é que se terá uma repercussão jurídica ou não para a antecipação terapêutica do parto.

Dentre os integrantes do Supremo, quem melhor parece ter percebido esse impasse hermenêutico foi o Ministro Carlos Ayres Britto, que, em seu voto-vista, referiu existirem três interpretações sobre 0 aborto neste caso: a) a de que a antecipação terapêutica do parto é crime, pois constitui uma interrupção do ciclo gestacional, tendo por fundamento a proteção ao nascituro conferida pelo ordenamento jurídico brasileiro (art. $2^{\circ}$ do Código Civil), bem como pelo Pacto de San José da Costa Rica (art. 4으, parágrafo $1^{\circ}$ ), caso em que o feto anencefálico é compreendido como sendo um ser vivo em sua plena dignidade e proteção jurídica; b) a de que inexiste crime, pois a antecipação do parto tem por objeto um natimorto fetal, sendo que, neste caso, a interrupção voluntária da gestação é penalmente atípica (com base analógica no art. 3 da Lei de Transplantes, que considera, conforme já referido, a morte encefálica como critério para a retirada de órgãos); c) a de que a antecipação do parto é fato típico, mas não punível, em face do abalo psíquico da mãe, entendido como um bem jurídico a tutelar, sendo comparável, em certa medida, à autorização legal para o estupro, havendo decisões jurisprudenciais para as três teorias.

Vista a controvérsia a partir dessa perspectiva, tem-se que até mesmo o apelo à figura da interpretação conforme à Constituição, na forma como proposta, torna-se desnecessário, pois a própria interpretação jurídica do conceito de feto e de vida é prejudicial e definitiva para a decisão.

A decisão em questão, contudo, não ingressou no mérito da discussão, remetendo a apreciação desses aspectos a um momento posterior.

Interessante notar, no entanto, que tão-somente nessa terceira e última hipótese suscitada é que se abre espaço para a possibilidade de ponderação de bens, conforme

33 KANT, Immanuel (1957): Grundlegung zur Metaphysik der Sitten, (Hamburg, M einer). 
pleiteado na inicial (dignidade da mãe, em face de seu sofrimento psicológico x dignidade do feto e direito à vida), tema que se revelou fundamental e decisivo no parecer da Procuradoria Geral da República e que, este sim, implicaria em inclusão, pela via interpretativa, de uma nova hipótese de aborto legal (entendido como conduta típica, porém não punível), caso em que o Judiciário estaria, supostamente, desempenhando papel tradicionalmente reservado ao legislador.

Neste sentido, a proporcionalidade de uma tal medida, no entanto, na verdade sequer é analisada ou enfrentada. A discussão permanece, antes, no âmbito de que há necessidade de proteção da vida intra-uterina independentemente das deformidades do feto, pois "todos nascemos para morrer", ${ }^{34}$ sendo que a duração dessa vida não pode ficar à disposição das pessoas; também o argumento de que o sofrimento não agride a dignidade humana, pois ele faz parte da vida, foi levantado, não sendo objetivo do ordenamento jurídico extirpar o sofrimento, caso em que a noção de dignidade humana parece ter uma conotação bastante restrita.

Chamam atenção, ainda, outros aspectos levantados na decisão, nem sempre diretamente conectados ao problema jurídico em pauta -pelo menos se considerados do ponto de vista técnico- constituindo-se, antes, em manifestações de ordem ideológica e/ ou fática. Neste sentido, podem-se destacar aspectos como a referência, feita pelo M inistro Carlos Ayres Britto, de que a discussão em pauta somente gerava tamanha controvérsia em razão de envolver uma questão essencialmente feminina, pois, segundo ele, "se os homens engravidassem, o aborto seria descriminalizado de ponta a ponta". ${ }^{35}$

Também os assim chamados votos de "política judiciária" merecem destaque neste ponto, especialmente nos votos dos M inistros M arco Aurélio e Sepúlveda Pertence. $\mathrm{Na}$ fundamentação do primeiro, percebe-se, nitidamente, uma preocupação com a função política e pacificadora da decisão, no sentido de se pôr um fim no que o M inistro denominou de "babel de decisões", fazendo menção à pluralidade de entendimentos e de posicionamentos jurisprudenciais ${ }^{36}$ que a temática vinha adquirindo, comprometendo, assim, a própria segurança e certeza jurídicas. Já o M inistro Sepúlveda foi mais longe, assumindo, expressamente, estar decidindo com base em questões estratégicas e de conveniência, e não de convencimento sobre a matéria. Segundo ele, "há tantos abortos praticados diariamente no Brasil que o cumprimento da

34 Voto do M inistro Cesar Peluzo. BRA SIL. Supremo Tribunal Federal (2004): Medida Cautelar na Argüição de Descumprimento de Preceito Fundamental 54-8/Distrito Federal, (Relator Ministro Marco Aurélio M ello, julgada em 20 out. 2004), p. 74.

35 Voto do Ministro Carlos Ayres Brito. BRASIL. Supremo Tribunal Federal (2004): Medida Cautelar na Argüição de Descumprimento de Preceito Fundamental 54-8/Distrito Federal, (Relator Ministro M arco Aurélio M ello, julgada em 20 out. 2004), p. 69.

36 Conforme já referido, vinham sendo constatadas decisões negando a antecipação do parto, bem como outras autorizando a prática; mesmo estas últimas, porém, com fundamentos e razões absolutamente distintos, como já referido em momento anterior do presente trabalho. 
liminar por alguns dias não será uma catástrofe", ${ }^{37}$ razão pela qual ele preferiu manter a cautelar autorizando a interrupção da gestação e não criar uma insegurança processual ainda maior.

\section{c) A anencefalia e o conflito dignidade da mãe $x$ dignidade do feto}

Por fim, o último aspecto a ser analisado, enquanto questão controversa, diz respeito à operacionalização do eventual conflito estabelecido, no caso, entre o direito à vida do feto e o direito à saúde e à dignidade da mãe (ponderação e proporcionalidade). Conforme já ressaltado, esta questão apenas adquire relevância, do ponto de vista da decisão, se se considerar válida a terceira hipótese de enquadramento levantada pelo M inistro Carlos Ayres Brito, isto é, o juízo de ponderação e de proporcionalidade somente ganha espaço, neste contexto, se se entender a antecipação terapêutica do parto, nos casos de anencefalia, como um fato típico, porém não-punível, funcionando o abalo psíquico da mãe como um fundamento para justificar a relativização de proteção do direito de vida ${ }^{38}$ da criança. Ter-se-ia, portanto, uma ponderação entre os bens jurídcos tutelados, típica de um conflito entre direitos fundamentais.

Segundo a lei de colisão, formulada por Alexy, em havendo um conflito entre princípios e/ ou direitos fundamentais, é preciso que se verifique, sempre, o caso concreto e que se estabeleçam os interesses opostos, em conflito, fazendo-se uma ponderação entre eles, a fim de se verificar qual deles possui maior peso naquele caso. A partir daí, o que se verifica é que um princípio pode, em determinadas circunstâncias, limitar a aplicação do outro, devendo, então, haver uma ponderação, a fim de se estabelecer o que 0 autor chama de uma relação de precedência condicionada. ${ }^{39}$

Desta forma, percebe-se que os princípios têm estreita relação com a noção da proporcionalidade, através de suas máximas parciais ou subprincípios: adequação (a relativização do direito contrário é justificada pela proteção e realização de um outro direito igualmente importante e protegido pela ordem jurídico-constitucional - no caso em tela, a dignidade e a proteção do sofrimento da mãe como fatores que justificariam à pretensão de sacrifício da vida do feto, tal qual ocorre nos demais casos de aborto legal previstas pela legislação), necessidade (que, para a realização de um direito, faça-se, realmente necessário, o sacrifício ou relativização do direito contrário

\footnotetext{
37 Voto do Ministro Sepúlveda Pertence. BRASIL. Supremo Tribunal Federal (2004): Medida Cautelar na Argüição de Descumprimento de Preceito Fundamental 54-8/Distrito Federal, (Relator M inistro M arco Aurélio M ello, julgada em 20 out. 2004), p. 89. A manutenção da liminar, no caso, se refere à autorização de antecipação do parto, concedida pelo Ministro Marco Aurélio.

38 Como já dito, esta posição pressupõe, por entender que a interrupção da gestação configura fato típico, tal qual o aborto, que o feto, apesar de sua deformidade, possui vida e é, portanto, sujeito de dignidade, protegido pelo ordenamento jurídico-constitucional.

39 A LEXY, Robert (1994): Theorie der Grundrechte, (Frankfurt a.M., Suhrkamp).
} 
- no caso da anencefalia, por exemplo, tem-se que o sofrimento da mãe reside exatamente na manutenção da gestação, não sendo possível, a um só tempo, interromperse a gestação e preservar a vida do feto) e proporcionalidade em sentido estrito (adequação entre meios e fins, ou seja, a restrição do direito fundamental contrário deve dar-se na intensidade mínima necessária à realização do direito em pauta, não se admitindo excessos). ${ }^{40}$

No julgamento, contudo, em momento algum pode ser percebido algum raciocínio ou fundamentação pautado num raciocínio de ponderação, sendo que a questão apenas é levantada retoricamente. Na verdade, sequer a percepção de que uma tal hipótese somente se aplica neste terceiro caso resta evidenciada, pois este argumento é reiteradamente suscitado, todavia de forma aleatória, desprovido de uma análise que revele uma adequada percepção do problema em sua real complexidade.

Ademais, além dos aspectos aqui ressaltados, é preciso referir que a maior parte dos argumentos levantados nos votos está relacionada tão-somente a aspectos formais (cabimento da liminar, análise da urgência da medida, etc.), não tendo havido um efetivo enfrentamento das questões materiais envolvidas.

Assim, percebe-se que, apesar da controvérsia e da polêmica presentes por ocasião do julgamento, com a manifestação de diferentes pontos de vista e perspectivas por parte dos M inistros, a complexidade da temática não foi devidamente aprofundada, tanto em termos jurídicos e técnicos - discussão sobre o cabimento da interpretação conforme à Constituição, condições da ponderação- quanto sociais (análise e percepção do problema social envolvido), sendo que os votos revelam uma complexidade de argumentos, mas os argumentos não revelam e enfrentam, de forma adequada, a complexidade do caso.

\section{CONCLUSÃO}

A nalisar um caso concreto significa, dentro da sistemática desenvolvida, conforme já referido, além do levantamento dos aspectos anteriormente suscitados, enfrentar, também, o caso em seu julgamento ou em seus desdobramentos jurisdicionais, como ponto de partida para uma eventual crítica ou abordagem das insuficiências em sua apreciação enquanto fenômeno jurídico-social por parte do Poder Judiciário.

40 Alexy vai estabelecer, para tanto, uma noção de "limites dos limites" (teoria dos Schranken-Schranken), segundo a qual a restrição de um direito fundamental, em caso de colisão, não pode ser tamanha, que implique em sua anulação. Assim, os direitos fundamentais podem ser limitados, mas mesmo esta limitação é limitada. Cf. Alexy, Robert (1994): Theorie der Grundrechte, (Frankfurt a.M., Suhrkamp), p. 267. No mesmo sentido, a teoria constitucional alemã vai construir uma noção de "núcleo essencial" (Wesensgehalt) referente aos direitos fundamentais, constituindo-se, assim, um núcleo imutável e intangível, que não admite restrições ou violações. Para tanto, ver BRÜnNECK, Wiltraut Rupp-von (1977): "Verfassungsgerichtsbarkeit und gesetzgebende Gewalt: wechselseitiges Verhältnis zwischen Verfassungsgericht und Parlament", en Archiv des öffentlichen Rechts (Band 102, Tübingen: J.C.B. Mohr). 
No caso da ADPF envolvendo a discussão acerca da possibilidade de interrupção da gestação em casos de fetos com anencefalia, percebe-se uma grande atenção dedicada a diferentes aspectos relacionados à temática, reveladora da complexidade do problema jurídico enfrentado, porém desprovida do devido desenvolvimento em termos teóricos e de fundamentação. Igualmente no que tange aos argumentos de cunho social da decisão é interessante perceber que o impacto social é brevemente suscitado como fator determinante para a concessão e para a manutenção da liminar, porém não verdadeiramente levado em consideração como fator decisivo para o julgamento.

Pode-se perceber, neste sentido, uma ausência de diálogo dos fatos com o direito, pois a questão acabou por ser resolvida, notadamente, com base em conceitos e em uma apreciação de cunho essencialmente político, onde a discussão ficou adstrita à conveniência ou não de uma decisão do Supremo Tribunal Federal sobre a matéria. M esmo neste ponto, entretanto, pode-se perceber uma ausência de aprofundamento e de esgotamento do debate, pois a leitura e o enquadramento dos conceitos jurídicos foram feitos de forma superficial, carente de maior aprofundamento analítico e discursivo. Tem-se, por conseguinte, que os elementos trazidos aos autos pelos julgadores revelam-se, em certa medida, frágeis tanto em sua apreciação fática quanto jurídica, revelando uma certa desconexão com a realidade social atingida.

Precisamos, enquanto operadores, aprender a lidar com a complexidade que caracteriza as relações sociais na atualidade e, para tanto, precisamos, também, aprender a complexificar as abordagens que fazemos do próprio direito, notadamente quando estamos diante de situações concretas, que envolvem e põem em jogo muito mais do que simples conceitos jurídicos abstratos. E a análise aqui traçada revelou exatamente a insuficiência deste enfrentamento, especialmente se se considerar que ele foi levado a cabo pela mais alta Corte do país, destinada a resolver controvérsias diretamente ligadas à Constituição e, portanto, intimamente associadas aos mais altos valores e princípios jurídicos e sociais da vida em comum de uma coletividade.

\section{REFERÊNCIAS}

AbelLÁn, M arina Gascón (2003): "Los límites de la jurisdicción constitucional", en LAPORTA, Francisco. Constitución: problemas filosóficos (Madrid, Centro de Estudios Políticos y Constitucionales).

A LEXY, Robert (1994): Theorie der Grundrechte (Frankfurt a.M .: Suhrkamp).

Ввонм, Winfried (2001): "Die Funktion des BVerfG - Oligarchie in der Demokratie?", en Neue Juristische Wochenschrift (Heft 01, 2001).

BRÜNNECK, Wiltraut Rupp-von (1977): “Verfassungsgerichtsbarkeit und gesetzgebende Gewalt: wechselseitiges Verhältnis zwischen Verfassungsgericht und Parlament", en Archiv des öffentlichen Rechts (Band 102, Tübingen, J.C.B. Mohr).

Dinız, Maria Helena (2001): $O$ estado atual do Biodireito (São Paulo, Saraiva).

FreIRE, A lexandre Reis Siqueira (2001): “A rgüição de Descumprimento de Preceito Fundamental: origem e perspectivas", en Revista da Faculdade de Direito da UFPR (Porto Alegre, ano 33, v. 35) p. 205-218. 
Hesse, Konrad (1999): Grundzüge des Verfassungsrechts der Bundesrepublik Deutschland (20. A uflage, Heidelberg, C. F. Müller).

KANT, Immanuel (1957): Grundlegung zur Metaphysik der Sitten (Hamburg, Meiner, 1957).

KeLSEN, Hans (1929): Wesen und Wert der Demokratie (Tübingen, M ohr).

KeLSEN, Hans (1929): “Wer soll der Hüter der Verfassung sein?”, en Die Justiz (Heft 1112, vol. VI) pp. 576-628.

LEAL, M ônia Clarissa Hennig (2007): Jurisdição Constitucional aberta: reflexões sobre a legitimidade e os limites da jurisdição constitucional na ordem democrática - uma reflexão a partir das teorias constitucionais alemã e norte-americana (Rio de Janeiro, Lumen Juris).

M Andelli JunioR, Roberto Mendes (2003): Argüição de Descumprimento de Preceito Fundamental: instrumento de proteção dos direitos fundamentais e da Constituição (São Paulo, Revista dos Tribunais).

M ENDES, Gilmar Ferreira (1998): Jurisdição constitucional: o controle abstrato de normas no Brasil e na Alemanha (2. ed., São Paulo, Saraiva).

M IrAndA, Jorge (2000): M anual de Direito Constitucional (4 ed., Coimbra, Coimbra).

RosA, Eugenio (2003): "Interpretação conforme a Constituição e controle difuso de constitucionalidade", en Andrade, André (org.). A constitucionalização do Direito: a Constituição como locus da hermenêutica jurídica (Rio de Janeiro, Lumen Juris).

SAm PAIO, José A dércio Leite (2002): A Constituição reinventada pela Jurisdição Constitucional (Belo Horizonte, Del Rey).

STRECK, Lênio Luiz (2001): “O s meios e acesso do cidadão à jurisdição constitucional, a Argüição de Preceito Fundamental e a crise de efetividade da Constituição brasileira", en Souza Cruz, Álvaro Ricardo de (org.). Hermenêutica e jurisdição constitucional (Belo Horizonte, Del Rey).

STRECK, Lênio Luiz (2002): Jurisdição constitucional e hermenêutica: uma nova crítica do Direito (Porto A legre, Livraria do Advogado).

ZagreBelSKY, Gustavo (1988). La giustizia constituzionale (2 ed., Bolonia, II Mulino). 